within a few days after the congress. The second point brought out shows why we have all failed so markedly to cure or relieve gonorrhea with vaccines.

Dr. Cart C. Warden, Ann Arbor, Mich.: There are two points that $I$ think need emphasizing. One is in regard to the presence or absence of protein or nitrogen in these lipoids. We cannot absolutely say that nitrogen is wholly excluded from this product, no matter how perfect our chemicals may be. I may say that this nitrogen, if it exists, is one of the essential parts, coupled with the fats.

In regard to the complement fixation, it seems very strange that we do not obtain a complement fixation test at all times during the course of gonorrhea. The question arises: why do we not, especially in the florid stages of gonorrhea, obtain a higher percentage of complement fixation test than we do. We shall always be embarrassed by this fact. I think the reason for it is fairly evident. Man is almost wholly immune to gonococcus to begin with. There are very few tissues left in the body on which the gonococcus is able to exist. The blood stream occasionally shows gonococcus infection but these cases are extremely rare. Now, then, those positions in the body that are subject to gonococcus infection happen to be extremely remote from the great laboratory of antibody formation, and for this reason it is a long time before the fluids of the body are enabled to form antibodies against the coccus. It is only when the disease is beginning to get pretty well along, in from the fourth to the eighth week, that complement fixation appears as a really established thing. The greater the amount of antigen the coccus gives to the body as a whole, in the great laboratory of antibody production, the sooner we will find complement fixation positive. When the deeper structures of the urethra become involved and the complications of gonorrhea appear and when the general conditions become manifest, then is the time we have the largest per cent. of complement fixation. These conditions, I think, we shall always have to contend against, and we shall never be able to find antigen which will fix the complement under all conditions. The old watery antigens act variously, according to their fatty contents. A new arrangement of the fats and new lipoids will fix complement in the largest percentage of cases. There is abundant work to be done on the subject..

Dr. Fred R. Charlton, Indianapolis: May I ask Dr Warden whether in his therapeutic experiments he has confined himself to autogenous or the heterogeneous?

Dr. Carl C. Warden: All strains of gonococcus. I have used every one that could be obtained in the ordinary course of the examination of patients. I have succeeded in getting together probably forty or fifty different strains. The work of Torrey, and a good many others, has shown that if a dozen or more strains are employed, those strains will probably embrace all the variations. I feel that by having a large number of strains I have covered all the different varieties that might occur. I do not attach any particular significance to autogenous vaccines. I think better results are obtained from using many strains than one.

Experimental Vivisection and the Rights of Animals.I cannot argue with the man who insists that his dog and his hog are as good as he is; that he has no right to restrain the one or to eat the other. If he refuses to eat meat, or eggs, drink milk, use leather, wool or other animal products for clothing or shelter; if he refuse to make counter attacks against the lions or serpents which attack him, he is consistent; I cannot argue with him; I can merely watch him go his way in the procession with the trilobite, the ichthyosaurus and the dodo. But intensely practical questions arise and must be met. And the life of a relatively few animals is placed against the life and health and comfort of the human race. The antivivisectionist insists that even if you grant that the injury to the guinea-pig or the rabbit or the horse will save the life of a child, you have no right to save it in that way. If there is not room in the life-boat for the woman and the dog you have no right to push out the dog to make room for the woman.-Samuel S. Maxwell, Science.

\section{PERFORATION OF THE BILIARY TRACT}

REPORT OF TWO CASES

HOWARD L. BEYE, M.D.

IOWA CITY, IOWA

Perforation of the biliary tract is so infrequent as to warrant the reporting of unusual cases. In the following two cases of perforation of the gallbladder, the patients were operated on by Dr. C. J. Rowan in the surgical clinic of the University of Iowa.

CASE 1.-History.-L. E., schoolboy, aged 11 years, referred by Dr. Sinning of Iowa City, on the afternoon of Sept. 7, 1914, while playing, received a blow in the abdomen from one of his playmates. This caused him to faint, and after gaining consciousness he was in so much pain that he screamed and had to be carried home. During the following night he complained of a great deal of pain, and was very restless. The next morning he vomited profusely, and the pain became worse on the left side, and was more marked here than on the right. The temperature ranged between 100 and 101 on this day. The bowels refused to move even with enemas and after calomel. There had been no chill.

The past history was negative, except that about two months before, the boy had received a blow in the abdomen, at which time he was sick for three days with a high fever and vomiting. The bowels were moved with difficulty. Following this he was apparently perfectly well until the present trouble.

Examination.-The patient was brought to the University Hospital at 8:30 p. m., September 8. At this time the temperature was 100.8 , pulse 100 , and respirations 40 . His face had a drawn, anxious look, and the respirations were rapid and shallow. He preferred to be on his side with the thighs and knees flexed, and complained of pain in the abdomen when moved. The walls of the abdomen were rigid; this was perhaps most marked in the right upper quadrant, though the patient complained mostly of pain in the left side. There was dulness in the right upper quadrant. No palpable masses. No cough. Heart and lungs negative. Leukocyte count 21,300 . A diagnosis of ruptured appendix and general peritonitis was made.

Operation.-Under ether anesthesia, a midline incision was made below the umbilicus. There was properitoneal edema. The abdomen contained a large amount of bile-stained fluid, and considerable fibrin in plaques. The proximal half of the small intestines was distended, and the distal half collapsed. The intestines were examined for perforation, and none found. The incision was carried up to the right of the umbilicus to the gallbladder region. The gallbladder was found to be thickened and adherent to the liver, and contained a single perforation in the fundus from which pure bile was pouring. No stones were found. A rubber tube drain was led down to the perforation, together with a cigaret drain and a strip of iodoform gauze. A rubber tube drain was led from the pelvis at the lower end of the incision. The usual closure was made.

Course.-The patient was placed in Fowler's position and given normal salt solution by rectum, and nothing per mouth. Recovery was uneventful. The patient left the hospital on the fifteenth day.

The interesting point about this case aside from the perforation is the chronic cholecystitis present in a child of 11 years. The relationship between the condition of the gallbladder and the injury received two months before the perforation is problematic. At that time the patient might have had an acute cholecystitis which was followed by gallbladder changes which predisposed to later perforation, or he might at that time have had a perforation of the gallbladder with a localized peritonitis which resolved. There is no his- 
tory of typhoid fever, and there were no attacks of tonsillitis to account for the gallbladder infection.

Case 2.-History.-Mrs. M. M., housewife, aged 57, referred by Dr. A. R. Lynn of Marshalltown, for several years had occasional attacks of belching of gas, sometimes with vomiting, independent of meals. In February, 1913, she suddenly had a severe tearing pain under the right costal margin, radiating to the pit of the stomach. Following this she vomited profusely for several hours. The pain lasted an hour or more, caused her to cry out in agony, and was finally relieved by a hypodermic. Four weeks following this attack she became jaundiced, and this condition persisted until the next fall. In July, 1913, she had a similar attack.

Ever since the first attack the right side has been tender, and a swelling gradually formed, pointing in the right flank above the iliac crest. This finally approached the surface, the skin overlying became reddened, and it was lanced. An odorless fluid was obtained, at first thin and yellow, and later thicker. This gave her immediate relief from her constant ache and pain. There has been a persistent discharge of a mucous secretion ever since, and recently she passed four wheat-sized calculi. The general condition was good except for an increasing gnawing, burning sensation in the epigastrium, not referable to food taking.

Examination.-This was negative except for the abdomen. In the right side, between McBurney's point and the gallbladder region, there was a palpable mass about the size of a small orange, quite tender. Leading down to this mass was a sinus from which a small amount of light yellow tenacious fluid was discharged.

Blood: Hemoglobin 78 per cent. (Sahli), leukocytes 9,300,

Gastric Analysis: Seventy-five c.c. in forty-five minutes. Total acidity 100 . Free hydrochloric, 68 . No blood.

Urine: Negative.

A diagnosis of mucous gallbladder fistula following perforation was made.

Operation.-Sept. 28, 1914, under ether anesthesia, a right rectus incision was made above the level of the umbilicus. The gallbladder was long and narrow, and was adherent slightly to the omentum, and at the fundus to the abdominal wall at the inner end of the fistulous tract. A large mulberry stone was impacted in the cystic duct. The gallbladder was excised from its connection to the abdominal wall, and cholecystectomy performed. Tube draining was carried to the stump of the cystic duct, and an iodoform gauze drain through the sinus.

Course.-This was uneventful except for the formation of a hematoma in the operative wound, and the passage of a small calculus from the old fistulous tract, following which the latter healed. The patient left the hospital Nov. 3, 1914.

One of the interesting points about this case was the very slight amount of adhesions around the gallbladder, considering the extent of the diseased condition which must have been present during the period preceding the discharge of the abscess through the abdominal wall:

Measles.-The essential points in regulations for the control of measles are: The case shall be recognized and isolated at the earliest possible moment; the premises on which the case is isolated shall be placarded; the patient shall be isolated for at least five days after the appearance of the exanthem; adults and children who have previously had the disease need not be restricted, but it is advisable to warn them as to the slight possibility of second attacks, and keep them under observation; children who have not previously had measles and who are in contact with cases, need not be restricted for seven days after contact, but should thereafter be isolated for at least ten days and carefully observed. Disinfection after measles is useless and unnecessary. Transmission of measles by third persons or fomites must be exceedingly rare, if it occurs at all.-Harold Farnsworth Gray, Jour. Infect. Dis., November, 1915.

\section{New and Nonofficial Remedies}

The Following additional articles have BeEN ACCEPTED by the Council on Pharmacy and Chemistry of the American Medical Association. Their acceptance has BEEN BASED LARGELY ON EVIDENCE SUPPLIED BY THE MANUFACTURER $O R$ HIS AGENT AND IN PART ON INVESTIGATION MADE BY OR UNDER THE DiRection OF THE Council. Criticisms and corRECTIONS ARE ASKED FOR TO AID IN THE REVISION OF THE MATTER BEFORE PUBLICATION IN THE BOOK "NEW AND NONOFFICIAL REMEDIES."

The Council desires physicians to understand that The ACCEPTANCE OF AN ARTICLE DOES NOT NECESSARILY MEAN A RECOMMENDATION, BUT THAT, SO FAR AS KNOWN, IT COMPLIES WITH THE RULES ADOPTED BY THE COUNCIL.

W. A. Puckner, Secretary.

STAPHYLOCOCCUS VACCINE (See N. N. R., 1915, p. 319.)-Swan-Myers Company, Indianapolis.

Swan's Staphylococcus Bacterin (No. 37).-Marketed in packages of six 1 Cc. vials, each containing 300 million Staphylococcus pyogenes
albus; also in $20 \mathrm{Cc}$. vials, containing 300 million Staphylococcus pyogenes albus per $\mathrm{Cc}$.

STREPTOCOCCUS VACCINE (See N. N. R., 1915, p. 322).-Swan-Myers Company, Indianapolis.

Swan's Streptococcus Bacterin (No. 43).-Marketed in packages of six 1 Cc. vials, each containing 120 million Streptococcus pyogenes; also in $20 \mathrm{Cc}$. vials, containing 120 million Streptococcus pyogenes

CALCIUM PEROXIDE (See N. N. R., 1915, p. 230).The following non-proprietary preparation has been accepted:

Calcium Peroxide, Merck.-Manufactured by E. Merck, Darmstadt, Germany (Merck and Co., New York).

SODIUM PEROXIDE' (See N. N. R., 1915, p. 232).-The following non-proprietary preparation has been accepted:

Sodium Peroxide, Merck.-Manufactured by E. Merck, Darmstadt, Germany (Merck and Co., New York).

ZINC PEROXIDE (See N. N. R., 1915, p. 234).-The following non-proprietary preparation has been accepted:

Zinc Peroxide, Merck.-Manufactured by E. Merck, Darmstadt, Germany (Merck and Co., New York).

ETHYL SALICYLATE (See N. N. R., 1915, p. 272).The following non-proprietary preparation has been accepted: Ethyl Salicylate, Merck. Manufactured by E. Merck, Darmstadt, Gernany. (Merck and Co., New York).

OSMIUM TETROXIDE (See N. N. R., 1915, p. 225).-The following non-proprietary preparation has been accepted: Osmic Acid, Merck.-Manufactured by E. Merck, Darmstadt, Germany (Merck' and Co., New York).

SODIUM OLEATE (See N. N. R., 1915, p. 348).-The following non-proprietary preparation has been accepted:

Sodium Oleate, Merck.-Manufactured by E. Merck, Darmstadt, Germany (Merck and Co., New York).

THIOSINAMINE (See N. N. R., 1915, p. 361).-The following non-proprietary preparation has been accepted:

Thiosinamine, Merck.-Manufactured by E. Merck, Darmstadt, Germany (Merck and Co., New York).

UREA (See N. N. R., 1915, p. 365).-The following nonproprietary preparation has been accepted: Urea, Merck.-Manufactured by E. Merck, Darmstadt, Germany
(Merck and Co., New York).

SODIUM CACODYLATE (See N. N. R., 1915, p. 49).The following dosage forms have been accepted:

Ampuls Sodium Cacodylate, Mulford, 73/4 grains.-Each ampule contains sodium cacodylate $0.5 \mathrm{Gm}$. (7\% grains). Prepared by $\mathrm{H}$. $\mathrm{K}$ Mulford Co., Philadelphia.

Ampuls Sodium Cacodylate, Mulford, 15 grains.-Each ampule contains sodium cacodylate $1 \mathrm{Gm}$. (15 grains). Prepared by $\mathrm{H}$, $\mathrm{M}: 1$

SOLUTION PITUITARY EXTRACT (See N. N. R., 1915, p. 223).-The following dosage form has been accepted: Ampuls Solution Pituitary Extract, Mulford, 0.5 C c. Each ampule contains solution pituitary extract $0.5 \mathrm{Cc}$. Prepared by $\mathrm{H}$. K. Mulford
Co., Philadelphia. 